\title{
Complement activation within the coeliac small intestine is localised to Brunner's glands
}

\author{
R B GALlagher, C P KELly, S NEVILLE, O SHEILS, D G WEIR, \\ AND C F FEIGHERY \\ From the Departments of Immunology, Histopathology and Clinical Medicine, Trinity College, Dublin, \\ Ireland
}

summary Complement activation may play an important role in the pathogenesis of coeliac disease. In the present study immunohistochemical localisation of C3 and of a neoantigen exposed only on the terminal C5b-9 complement complex has been performed on small intestinal biopsy sections from newly diagnosed untreated coeliac patients, from coeliac patients on long-term glutenfree diet and from disease controls. Levels of $\mathrm{C} 3$ were markedly increased in treated coeliac patients compared with controls. Staining of $\mathrm{C} 3$ was concentrated subepithelially and within the centre of the lamina propria. No staining was detected at these sites using antibody to the neoantigen, however, strongly suggesting that the increased levels of $\mathrm{C} 3$ seen in the coeliac patients was the result of increased extravasation of serum proteins rather than complement activation. Surprisingly, complement activation was detected within the glands of Brunner. Positive staining using anti-C5b-9 neoantigen was found in all coeliac patients, both treated and untreated. Three of the 13 disease controls also showed reactivity with this antibody. This novel finding suggests that Brunner's glands, hitherto largely neglected structures, may play an important role in the development of coeliac disease.

Although the pathogenic mechanism in cocliac disease is not yet fully understood, involvement of the immune system is generally accepted. Antibody, ${ }^{1-3}$ complement, ${ }^{+7}$ T cell, ${ }^{-11}$ and mast cell ${ }^{11}$ responses at the site of disease activity have all been reported but the relative contribution of each of these factors remains unclear. Evidence for participation of complement in the disease process comes from the finding of reduced levels of serum concentrations of some complement components ${ }^{+}$and from immunohistochemical localisation of large quantities of complement within the coeliac small bowel. ${ }^{-7}$ It is not known, however, whether the complement detected in the coeliac intestine is activated, and therefore involved in damaging processes, or is present in native form, simply as a result of increased

Address for correspondence: Dr Richard B Gallagher. Department of Immunology. Trinity College Medical School, St James Hospital, Dublin 8 . Ireland.

Accepted for publication I March 1989. extravasation of serum proteins. In this study we have addressed this question by using a monoclonal antibody which detects a neoantigen exposed only on formation of the terminal C5b-9 complex. Thus complement activation in the coeliac small bowel, through either classical or alternate pathway, is detectable using this antibody.

\section{Methods}

SMAI.I. INTESTINAI. BIOPSIES

Intestinal biopsies, taken at endoscopy from the distal duodenum, were obtained from 10 coeliac patients and 13 disease controls. Five of the coeliac patients were newly diagnosed, with characteristic histological abnormalities which showed improvement on subsequent gluten free diet. The other five coeliac patients were on longterm gluten free diet (Table 1). The diagnosis of the 13 disease controls are shown in Table 2. The tissues were embedded in OCT, snap frozen and stored at $-70^{\circ} \mathrm{C}$ until used. 
Table 1 Dietary and histological status of treated coeliac patients

\begin{tabular}{|c|c|c|c|}
\hline Patient & $\begin{array}{l}\text { Dietary } \\
\text { compliance }\end{array}$ & Duration & Histology \\
\hline 1 & Strict & 1 year & Normal \\
\hline 2 & Strict & 17 years & Normal \\
\hline 3 & Fair & 12 years & Subtotal villous atrophy \\
\hline 4 & Strict & 2 years & $\begin{array}{l}\text { Minimal villous blunting, no } \\
\text { inflammation }\end{array}$ \\
\hline 5 & Strict & 3 years & Normal \\
\hline
\end{tabular}

\section{IMMUNOHISTOIOGICAI. STAINING OF TISSUE}

SECTIONS

Cryostat sections $(5 \mu \mathrm{m})$ were cut, air' dricd overnight and fixed for four minutes in acetone. When staining, tris-buffered saline (TBS) $0.5 \mathrm{M}, \mathrm{pH} 7.6$ was used as the buffering system throughout and each step was followed by a wash in TBS.

To study complement activation, slides were incubated for 20 minutes in 1/50-diluted ascites fluid containing monoclonal antibody against a neoantigen on the C5b-9 complex (clone 3B1), a gift from Dr S Bhakdi, University of Giessen, FGR. Omission of the primary monoclonal antibody served as a
Table 2 Diagnoses of control group)

\begin{tabular}{ll}
\hline Patient & Endescopic findings \\
\hline 1 & Duodenal ulcer \\
2 & Duodenal ulcer \\
3 & Duodenitis \\
4 & Duodenitis \\
5 & Duodenitis \\
6 & Ciastric ulcer \\
7 & Antral gastritis \\
8 & Normal** \\
9 & Normal* \\
10 & Normal* \\
11 & Normal* \\
12 & Normal* \\
13 & Normal \\
\hline
\end{tabular}

*Clinical diagnosis: irritable bowel syndrome: Investigated for recurrent. severe aphthous stomatitis, duodenal biopsy normal.

negative control. The nature and specificity of the 3B1 antibody have been previously confirmed. ${ }^{1314}$ Binding of the antibody was visualised using either the immunoperoxidase (according to Kelly et al, $1987)^{15}$ or alkaline phosphotase $\mathrm{e}^{1 \mathrm{t}}$ staining methods. Results obtained by the two methods were identical.

On some sections polyclonal rabbit antiscra

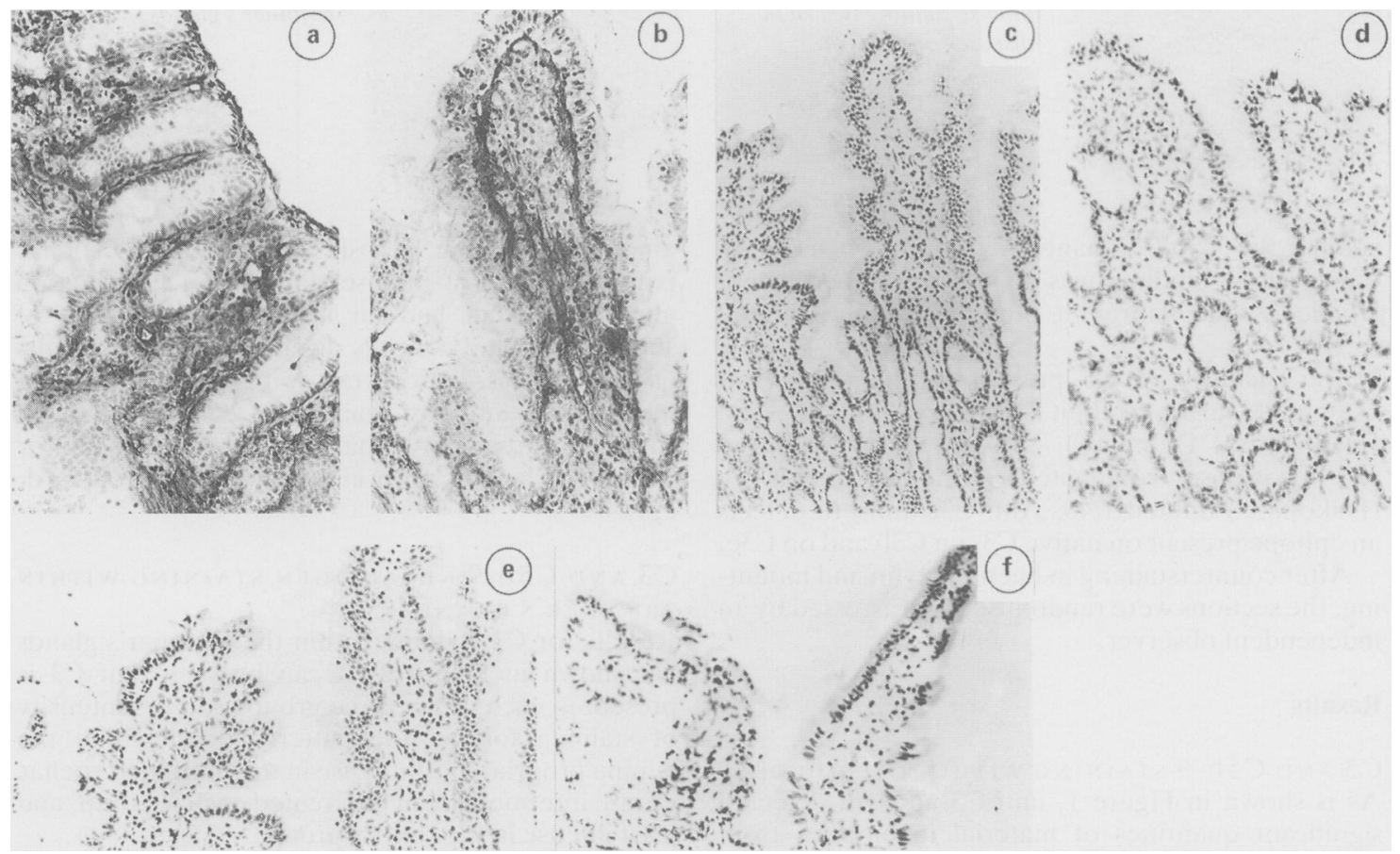

Fig. 1 C3 and C5b-9 neoantigen deposition in the small intestine. Strong C3 staining was found subepithelially in untreated coeliac disease (a) and both subepithelially and within the lamina propria of treated coeliac disease (b). In disease controls much less intense C3 staining subepithellialy and within the lamina propria was observed (c). C5b-9 staining was completely absent in untreated coeliac disease (d), coeliac patients on gluten free diet (c), and disease control patients (f). 


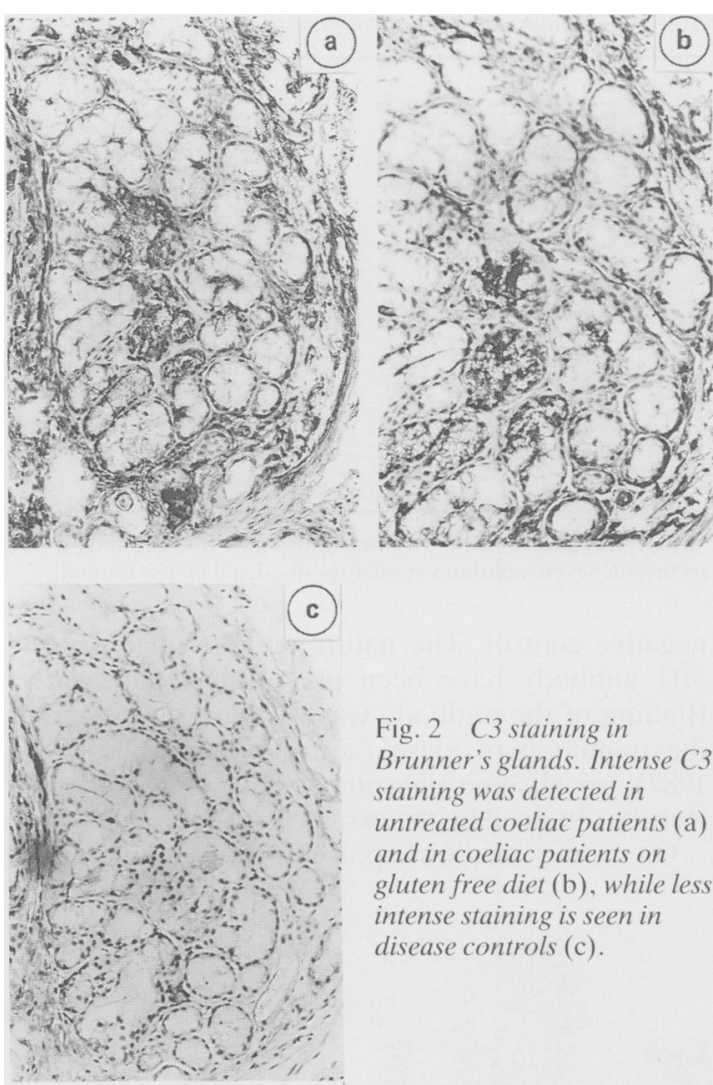

against the C5b-9 neoantigen were also used. In these cases binding was assessed by peroxidase labelled swine antirabbit immunoglobulin, diluted $1 / 20$.

The quantity of $\mathrm{C} 3$ present in the tissue was examined using rabbit antihuman $\mathrm{C} 3 \mathrm{c}$ sera (Dakopatts, Denmark) diluted 1/60), followed by peroxidase conjugated swine antirabbit Ig (Dakopatts) diluted 1/40. Anti-C3c antisera detects an epitope present on native $\mathrm{C} 3$, on $\mathrm{C} 3 \mathrm{~b}$ and on $\mathrm{C} 3 \mathrm{c}$.

After counterstaining in hacmatoxylin and mounting, the sections were randomised and assessed by an independent observer.

\section{Results}

C3 AND C 5b-9 STAINING WITHIN THE MUCOSA As is shown in Figure 1, anti-C3 antisera detected significant quantities of material in biopsies from all three groups studied. The pattern of staining, subepithelially and down the centre of the lamina propria was similar in every case. There were, however, marked quantitative differences in the

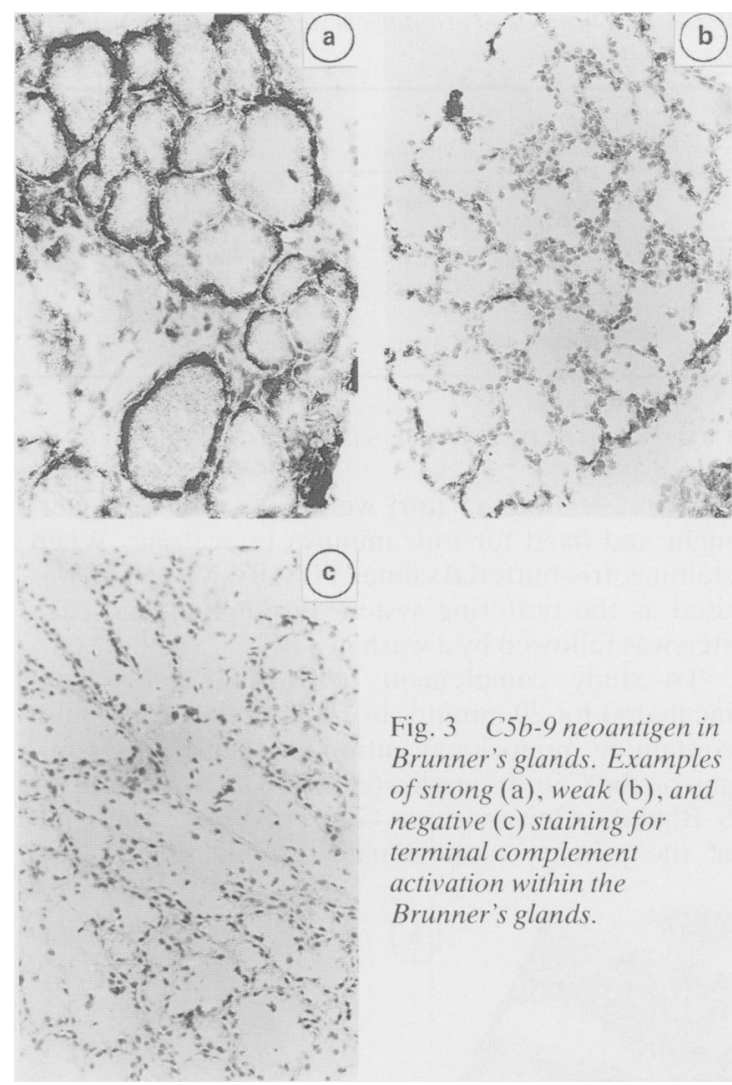

amount of staining; biopsies from untreated coeliac patients had most intense staining (a), patients on gluten free diet had an intermediate amount of staining (b), and controls displayed lowest amounts of staining (c). In contrast with C3 staining, the monoclonal antibody against the C 5 b- 9 neoantigen showed no reactivity whatsocver subepithelially or within the lamina propria in any of the groups $(\mathrm{d}$, e, f).

C3 AND C 5 b-9 NEOANTIGEN STAINING WITHIN BRUNNER`S GLANDS

Results for $\mathrm{C} 3$ staining within the Brunner's glands are shown in Figure 2. It can be seen that $\mathrm{C} 3$ is present in each of the three groups and the intensity of staining follows the pattern found within the lamina propria: most intense in the untreated coeliac group, intermediate in the treated cocliac group, and least intense in the control group.

Examination of staining by the monoclonal antibody to the neoantigen of the C5b-9 complex revealed a distinct and unique selectivity for the glands of Brunner in cocliac patients (Fig. 3 and 
Table 3 C5b-9 neoantigen staining within Brunner's gland

\begin{tabular}{|c|c|c|c|}
\hline \multirow[b]{3}{*}{ Group } & \multicolumn{3}{|l|}{ Staining } \\
\hline & \multirow[t]{2}{*}{ Negative } & \multicolumn{2}{|c|}{ Positive } \\
\hline & & Weak & Strong \\
\hline Disease controls $(n=13)$ & 10 & $2 *$ & $1+$ \\
\hline Combined coeliac patients $(n=10)$ & 0 & 5 & 4 \\
\hline Untreated coeliac patients $(n=5)$ & 0 & 2 & 3 \\
\hline Treated coeliac patients $(n=5)$ & () & 4 & $1 \%$ \\
\hline
\end{tabular}

*Patients 8 and 13. Table 2: †Patient 6. Table 2: tPatient 1. Table 2.

Table 3). In all 10 biopsies from cocliac patients neoantigen was detected within the glands. The intensity of staining varied and was assigned as being cither strong (Fig. 3a) or weak (Fig. 3b). The extent of staining was also variable, though in each case between one third and two thirds of all lobules of the gland were affected. Of the 12 disease controls examined three had evidence of complement activation, one staining strongly (patient no 6, Table 2) and two weakly (patients 8 and 13, Table 2).

Using the polyclonal antisera to the complement neoantigens on a limited number of samples, identical findings to those for the monoclonal antibody were obtained (results not shown).

\section{Discussion}

The two major findings of this report are that (i) there is no activation of complement within either the epithelial or lamina propria compartments of the coeliac small intestine and (ii) complement activation, exquisitely restricted to the glands of Brunner, is detectable in coeliac patients.

The involvement of complement in the disease process was proposed a number of years ago on the basis of immunohistochemical staining showing $\mathrm{C} 3$ deposition in conjunction with $\operatorname{Ig}$ A (5), IgA plus IgG (7), or IgM (6). In all of these studies the suggested mechanism was complement activation secondary to immune complex deposition in the basement membrane zone and lamina propria. IgA, the most frequently reported isotype in the immune complexes, was said to activate complement via the alternate pathway. $\operatorname{IgA}$, however, has only been found capable of complement activation under very artificial conditions, such as chemical or interfacial aggregation of human myeloma $\operatorname{Ig} \mathrm{A}^{1 \times 10}$ while naturally occurring $\operatorname{Ig} \mathrm{A}$ immune complexes and cross linked IgA oligomers are incapable of complement activation either in vivo or in vitro. ${ }^{2 \prime \prime}$ An alternative explanation for the immunohistochemical findings in coeliac disease is that greater non-specific extravasation and retention of $\mathrm{C} 3$, along with other serum proteins, is occurring. This is the case in other heavily inflammed tissue with exudation and oedema, such as in Crohn's disease, where considerably increased quantities of serum proteins have been shown to accumulate extravascularly."

In this study we have repeated $\mathrm{C} 3$ staining in the cocliac lamina propria and obtained results consistent with previous studies, namely that there is a quantitative increase in the amount of $\mathrm{C} 3$ within the cocliac lamina propria. Resolution of the question of whether or not this complement is activated was made possible by the development of monoclonal and polyclonal antibodies against neoantigens present only on the activated C.5b-9 complement complex. Using such reagents we have shown that no complement activation occurs either subepithelially or within the lamina propria in the coeliac mucosa despite the larger increase in concentration of $\mathrm{C} 3$. This strongly suggests that complement activation plays no part in the disease process at these sites and accumulates by non-specific mechanisms.

Complement activation was, however, detectable at a different site in cocliac biopsies: all 10 patients examined had deposition of the C5b-9 complex within the glands of Brunner. In contrast, complement activation at this site was found in only three of 12 disease controls.

Brunner's glands are located in the submucosa of the duodenum, being most numerous in the proximal portion. Interestingly, the mucosal abnormalities of cocliac disease are also most marked in the proximal duodenum."- Brunner's glands have been shown to secrete mucus, bicarbonate and epidermal growth factor (EGF), agents which are important in mucosal defence and repair processes..$^{23}$ Thus complementmediated attack on these glands may seriously compromise mucosal defence by interfering with secretion of these factors. This possibility is currently under investigation.

Deposition of the terminal complement complex occurs within Brunner's gland, not only in untreated cocliac patients but also in patients on long term gluten free diet in whom marked clinical and histological improvement has been noted. This suggests that continuing complement activation occurs in spite of strict adherence to gluten free diet. An alternative explanation is that the complement was deposited while the patients were still on gluten containing diet. This is very unlikely as the half life of terminal complement complexes on the surface of nucleated cells is measured in minutes. ${ }^{2+25}$

At present there is no obvious explanation for the finding of complement activation in three of the controls with no apparent duodenal abnormalities. In 
two of these staining was very faint but in the third it was strong.

The pathway by which the complement is activated within the Brunner's glands remains to be elucidated. Possible mechanisms include (i) entrapment of immune complexes within the gland with subsequent activation of the classical pathway, (ii) deposition of a complement activating autoantibody, and (iii) alternate pathway activation. Immune complexes have been described in the circulation of patients with cocliac discase, including those on gluten free dict, and in the majority of cases they can fix complement. ${ }^{+}$Sequestration of these complexes within the Brunner's glands is therefore potentially important to the disease process. Unfortunately, at present, there is no information on the antibody or antigenic component of these complexes. An alternative explanation, that an autoantibody directed against an antigen on Brunner's gland is responsible for complement activation, is currently under investigation. Such an antibody would raise the possibility that cocliac disease, in common with many other HLA DR3-associated diseases, is initiated by a tissue specific autoimmune attack. Whatever the mechanism we are left with the intriguing possibility that damage to Brunner's gland leading to loss of mucosal defence and repair capability is an important factor in the development of gluten sensitive enteropathy.

The gift of monoclonal antibody 3B1 from Dr Sucharit Bhakdi, University of Giessen, FRG, is gratefully acknowledged. Thanks also to Dr Alex Whelan for stimulating discussion and to Drs D Nunes, V Pippet, and $\mathrm{K}$ Trimble for biopsy material. SN was funded by the Health Research Board of Ireland. RBG is a Wellcome Trust lecturer.

\section{References}

1 Baklcin K. Bracntzig P. Fausa O. Immunoglobulins in jejunal mucosa and scrum from patients with adult cocliac disease. Scand J Gastroenterol 1977; 12: 149-59.

2 Scott H, Ek J, Baklein K, Braentzig P. Immunoglobulinproducing cells in jejunal mucosa of children with cocliac disease on a gluten-free diet and after gluten challenge. Scand J Gastroenterol 1980; 15: 81-8.

3 Scott BB, Goodall A. Stephenson P. Jenkins D. Small intestinal plasma cells in coeliac disease. Gut 1984; 25: $41-6$.

4 Mohammed J, Holborrow EJ. Fry L. Thompson BR. Hoffbrand AV. Stewart JS. Multiple immune complexes and hypocomplementaemia in dermatitis herpetiformis and cocliac discase. Lancet 1976; ii: 48790 .

5 Shiner M, Ballard J. Antigen-antibody reactions in jejunal mucosa in childhood cocliac disease after gluten challenge. Lancet 1972: i: 1202.
6 Doe WF, Henry K, Booth CC. Complement activation in coeliac disease. In: Hekkens WThJM. Pena AS, eds. Coeliac disease. Leiden. 1980: 189.

7 Scott BB. Scott DG. Losowsky MS. Jcjunal mucosal immunoglobulins and complement in untreated cocliac discasc. J Pathol 1976; 121: 219-3.

8 Ferguson A. Murray D. Quantitation of intra-cpithelial lymphocytes in human jcjunum. Gut 1971; 12: 98894.

9 Marsh MN. Abnormal behaviour of epithelial lymphocytes in spruc. Gastroenterology 1980; 78: 1218.

10 Kelly J, O`Farrelly C, O`Mahony C, Weir DG, Feighery C. Immunoperoxidase demonstration of the cellular composition of the normal and coeliac small bowel. Clin Exp Immunol 1987: 68: 177-88.

11 Marsh MN, Hinde J. Inflammatory component of celiac spruc mucosa. I. Mast cells, basophils and cosinophils. Gastroenterology 1985; 89: 92-101.

12 Wingren U, Hallert C, Norrby K, Enerback L. Histamine and mucosal mast cells in gluten enteropathy. Agents Actions 1986; 18: 266-8.

13 Hugo F, Jenne D. Bhakdi S. Monoclonal antibodies to neoantigens of the C.5b-9 complex of human complement. Biosci Rep 1985; 5: 649.

14 Schafer H, Mathey D. Hugo F. Bhakdi S. Deposition of the terminal C.5b-9 complex in infareted areas of human myocardium. J Immunol 1986; 137: 194.5-9.

15 Kelly J. Whelan CA. Weir DG, Feighery C. Removal of endogenous peroxidase activity from cryostat sections of immunoperoxidase visualisation of monoclonal antibodies. J Immunol Meth 1987; 96: 127-32.

16 Cordell JL, Felini B, Erbes WN, et al. Immunoenzymatic labeling of monoclonal antibodies using immune complexes of alkaline phosphotase and monoclonal anti-alkaline phosphotase (APAAP complexes). J Histochem Cytochem 1984: 32: 219.

17 Bhakdi S, Mihly M. Roth M. Isolation of specific antibodies to complement components. Methods Enzymol 1983; 93: 409 .

18 Gotze O, Muller-Eberhard HJ. The C.3-activator system: an alternative pathway of complement activation. J Exp Med 1971; 134: 905.

19 Boakle J, Pruitt KM, Mesteskey J. The interactions of human complement with interfacially aggregated preparations of human secretory $\operatorname{IgA}$. Immunochemistry 1974: $11: 543$.

20 Imai H, Chen A, Wyatt RJ, Rifai A. Lack of complement activation by human IgA immune complexes. Clin Exp Immunol 1988: 73: 479-83.

21 Baklein K. Braentzig P. Immunohistochemical localization of complement in intestinal mucosa. Lancet 1974; ii: 1087-8.

22 Thompson H. Pathology of coeliac disease. In: Morson $\mathrm{BC}$, ed. Current topics in pathology-pathology of the gastrointestinal tract. Berlin: Springer-Verlag, 1985: 4975.

23 Shorrock CJ, Rees WDW. Overview of gastroduodenal mucosal protection. Am J Med 1988; 84 (suppl 2A): 2534.

24 Ramm LE, Whitlow MB, Koski CL. Shin ML, Mayer MM. Elimination of complement channels from the plasma membrane of U937, a nucleated mammalian cell 
line: temperature dependence of the elimination rate. J Immunol 1983; 131: 1411-5.

25 Carney DF, Koski CL. Shin ML. Elimination of terminal complement intermediates from the plasma membrane of nucleated cells: the rate of disappearance differs for cells carrying $(5 \mathrm{~b}-7$ or $(5 \mathrm{~b})-8$ or a mixture of C.5b-8 with a limited number of C.5b-9. J Immunol 198.5 : 134: 18(04-9. 